\section{Conclusions}

The introduction of unified budgets for primary care groups will have major implications for general practitioners. Key objectives for primary care groups will include greater interpractice working, improved financial and information systems, and methods of sharing data among practices. For many general practitioners, the most unpopular aspect of the changes will be that they will have to take much more responsibility for deciding about the prioritisation of services and for controlling prescribing costs and hospital budgets. General practitioners may find that these tasks do not fit well with their role as patients' advocates.

Contributors: AM and L M jointly planned and wrote the paper and are guarantors for the paper.

Competing interests: None declared.

Funding: None.

1 Secretary of State for Health. The new NHS. London: Stationery Office, 1997.

Dixon J, Mays N. New Labour, new NHS? BMJ 1997;315:1639-40.

3 Judge K, Mays N. Allocating resources for health and social care in England. BMJ 1994;308:1363-6.

Majeed A, Head S. Capitation based prescribing budgets. BMJ 1998;316:748-50.

5 Greenhalgh T. Effective prescribing at practice level can and should be identified and rewarded. $B M J$ 1998;316:750-4.
6 Dixon J, Holland P, Mays N. Developing primary care: gatekeeping, commissioning and managed care. BMJ 1998;317:125-8.

7 NHS Executive. The new NHS: modern and dependable. Establishing primary care groups. Leeds: NHSE, 1998. (HSC 1998/139.)

8 Klein R, Maynard A. On the way to Calvary. BMJ 1998;317:5.

9 Mays N, Goodwin N, Killoran A, Malbon G. Total purchasing: a step towards primary care groups. London: King's Fund, 1998.

10 Scally G, Donaldson LJ. Clinical governance and the drive for quality improvement in the new NHS in England. BMJ 1998;317:61-5.

11 Bevan G. Taking equity seriously: a dilemma for government from allocating resources to primary care groups. BMJ 1998;316:39-42.

12 Coulter A. Managing the demand at the interface between primary and secondary care. BMJ 1998;316:1974-6.

13 Malcolm L. Capitated primary care: policy, problems and prospects. Health Manager 1998;5:7-9.

14 Majeed A. Adapting routine information systems to meet the requirements of primary care groups. Public Health Med 1999;1:6-13.

15 Sims A, Redgrave P, Layzell A, Grimsley M, Wisher S, Martin D. Funding a primary care led NHS: achieving a model for more equitable allocation of healthcare resources at a sub-district level. J Public Health Med 1997; 19:380-6.

16 Pollock AM. The American way. Health Serv J 1998 April 9:28-9.

17 Goodwin N, Mays N, McLeod H, Malbon G, Raftery J. Evaluation of total purchasing pilots in England and Scotland and implications for primary care groups in England: personal interviews and analysis of routine data. BMJ 1998;317:256-9.

18 Malcolm L. GP budget holding in New Zealand: lessons for Britain and elsewhere. BMJ 1997;314:1890-2.

19 Malcolm L. Towards general practice led integrated health care in New Zealand. Med J Aust 1998;169:147-50.

20 Gilley J. Meeting the information and budgetary requirements of primary care groups. BMJ 1999;318:168-70.

(Accepted 18 December 1998)

\title{
Setting budgets for general practice in the new NHS
}

\section{Peter C Smith}

Centre for Health Economics,

University of York York YO10 5DD

Peter C Smith, professor of economics

pcs1@york.ac.uk

BMJ 1999;318:776-9
The centre of the new arrangements for the NHS is the establishment of primary care groups. ${ }^{1}$ Budgetary control will be a central concern of these new groups, and the principal instrument for securing that control will be the setting of an indicative budget for each general practice within a primary care group. Although this measure may go some way towards securing the required control, I believe that setting practice level budgets carries potentially serious adverse consequences. This article sets out the problems that health authorities and primary care group management will have to be alert to.

\section{Primary care groups}

Primary care groups will be based on all the practices within a geographically defined area covering a population of about 100000 . The groups will receive annual budgets, within which they will be expected to meet virtually all the health care needs of their population. The size of the budget will be determined by the health authority in which the primary care group lies and will be guided by a long term expenditure target set by the NHS Executive. ${ }^{2}$

Primary care groups are unusual managerial creations. Membership is compulsory, and the constituent practices of a primary care group will be jointly responsible for adherence to its budget. Yet it is not clear how individual general practices will be held to account for their expenditure. The white paper envisages four levels of primary care group, ranging

\section{Summary points}

Primary care groups about to be established in the "new NHS" will need to maintain budgetary control at the same time as securing health improvements and commissioning and providing services

An important mechanism for securing budgetary control is likely to be setting "indicative" health care budgets for individual general practices

However good the formula for setting such budgets, actual expenditure will diverge substantially from budget in many practices

Much of this divergence will be beyond the control of general practitioners

A system of budgets for general practices could also result in loss of fairness between patients and disillusionment among general practitioners

Any budgetary system should be implemented with great caution, and, at least initially, the associated rewards and penalties for general practices should be modest 
from a mainly advisory role (level 1 ) to a freestanding body responsible for commissioning and providing care (level 4). ${ }^{1}$ This implies progressively increasing freedom of action and responsibility for the budget.

Whatever level of responsibility a primary care group is operating at, securing budgetary control will be a high priority. However, the number of managerial devices available to secure such control is limited. One possibility is to adopt clinical guidelines in order to reduce variations in referral practice. However, the main instrument for securing control will probably be setting budgets for individual practices.

\section{Experience with practice budgets in the NHS}

The NHS has used practice budgets before. The fundholding initiative gave participating practices budgets for purchasing certain elective procedures and prescriptions..$^{3-8}$ However, the scheme covered only about $15 \%$ of hospital and community health service expenditure and the budgets (at least in the early years) were relatively generous. ${ }^{9}$ Participation was voluntary, and health authorities assumed responsibility for making good most of any "overspend" by fundholders. Thus, fundholding did not by most criteria constitute a demanding budgeting system, although there is some evidence that it helped contain prescribing costs. ${ }^{10}{ }^{11}$ Standard fundholding will be dismantled under the new arrangements.

In addition to fundholding, since 1991 all practices have been set indicative prescribing budgets under the Indicative Prescribing Scheme. This scheme has had little effect on prescribing practice, probably because of a lack of any associated incentives. ${ }^{1011}$

The total purchasing pilots more closely resemble the arrangements envisaged within primary care groups. In this experiment almost all health care expenditure was devolved from a health authority to the total purchasing site, which typically entailed about three practices. The most serious difficulties emerging from evaluation of the scheme have been the associated increase in managerial costs and the difficulty of identifying a "fair" budget. ${ }^{12}$

\section{Model of expenditure variation}

A satisfactory budgetary formula for individual practices should offer an unbiased estimate of the expected level of expenditure within each practice if it were to respond to the needs of its patients in a standard fashion. Yet, even if the technical difficulties of developing such a formula can be overcome, expenditure is likely to vary considerably from that predicted by any formula. ${ }^{13}{ }^{14}$ Variation in practice expenditure can be divided into five types (box).

The variability predicted by the formula must be based on the limited amount of patient data universally available-namely, age, sex, and area of residence. Clearly age will be a fundamental component of any model of use. For example, in the acute sector old people use about 10 times more health resources than adolescents. Moreover, the York acute sector needs index varies from $61.0 \%$ of the national average per capita (part of Welwyn) to $150.3 \%$ (part of Newcastle
Sources of variation in practice expenditure

- Variability in use predicted by the formula

- Systematic variations caused by known patient characteristics that are not captured by the formula

- Variations in clinical practice

- Random variations in levels of sickness within the practice population

- Variations in the prices of treatments

upon Tyne), confirming the need also to adjust for area-wide social factors. ${ }^{15}$

Observable characteristics of individual patients will inevitably occur that cannot be encompassed within the chosen needs formula and yet imply predictable variations in use from the formula. Chronic illness is the most obvious such medical characteristic, and purchase of private medical insurance is an important social characteristic. Evidence from the United States suggests that the most important measurable characteristic of this sort is the patient's previous use of health care. ${ }^{16}$

Variations in clinical practice are likely to form a large part of the variations in observed expenditure. ${ }^{17}$ Yet only part of any such variation will be under the control of the general practitioner. Some may be influenced by specialists and some by unavoidable social factors such as distance from hospitals.

Random variations in levels of sickness are very large for individual patients. It is, for example, absurd to expect every patient in the small area in Welwyn mentioned above to use $61 \%$ of the national average health care resources every year. Rather, the $61 \%$ refers to a population average over the long run.

Variations in the prices of treatments may be large, as substantial autonomy remains about how health care is purchased. Wide variations in prices for individual procedures have been observed under the internal market. ${ }^{18}$

Martin et al considered variations arising from patient characteristics, clinical practice, and levels of sickness and concluded that for populations of 10000 there is a 1 in 3 chance of expenditure varying more than $10 \%$ from a "fair" annual budget. ${ }^{14}$ For populations of 100000 the probability drops to 0.0026 , indicating the crucial role of population size in diversifying risk and hinting at the difficulties that will arise in setting health care budgets for small populations.

\section{Policy implications}

If significant sanctions or rewards were to be attached to variations in expenditure from budgets, general practices can be predicted to respond in various ways. ${ }^{19-28}$ They can be summarised as follows. ${ }^{29}$

Firstly, practices that perceive that their expenditure will fall below their budget may "spend up" in order to protect their budgetary position in future years. Secondly, practices that perceive that their expenditure will exceed their budget may be thrown into crisis. Thirdly, patients may be treated inequitably. Different practices will be under different budgetary pressures and so may adopt different treatment 


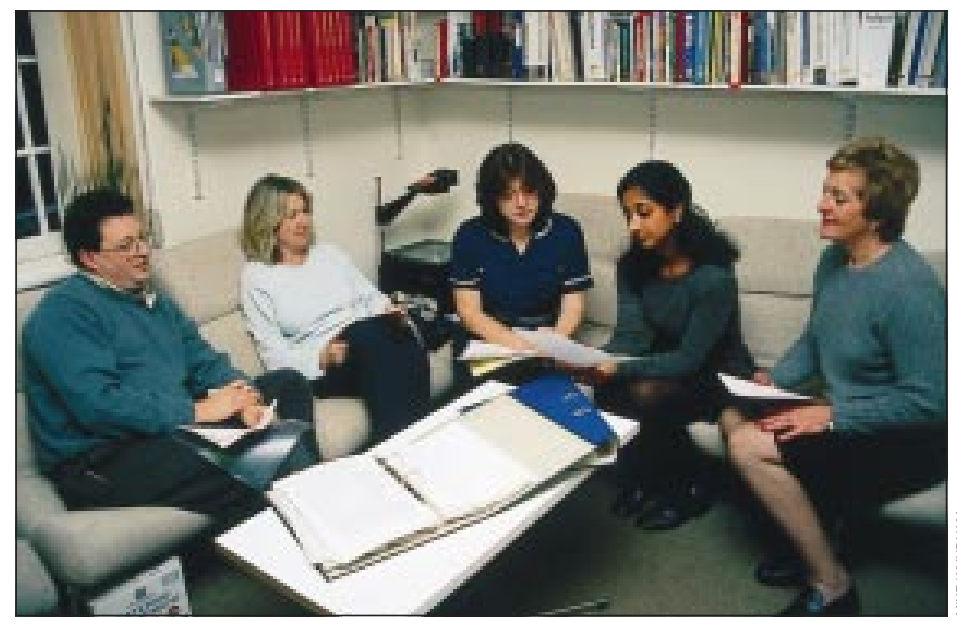

Budget meeting in a general practice

practices. Moreover, choice of treatment within a practice may vary over the course of a year if the practice's perception of its budgetary position changes. ${ }^{30} 31$ Fourthly, practices may adopt a variety of defensive strategies, such as cream skimming patients they perceive to be healthier than implied by their capitation $^{32}$ and, in the extreme, even insuring with a third party against overspending their budget. More generally, if the complex and subtle influences on variation are not properly recognised, practices may become alienated from the budgetary system, jeopardising budgetary control throughout the NHS and threatening the viability of the latest NHS reforms.

Nevertheless, I would not argue that primary care groups should refrain from setting practice budgets. Rather, they should use them with great caution and ensure that the budgets reflect legitimate variations in health care needs. Various risk management strategies might be adopted to lessen some of the adverse consequences outlined above.

Pooling practices-Budgets become less susceptible to random per capita variations as the population to which they refer increases. This suggests allocating a joint budget to voluntary associations of practices that wish to collaborate. However, evidence from the total purchasing pilots suggested that budgetary control was more difficult in multipractice sites than single practice sites, ${ }^{12}$ highlighting an important tension that exists between the goal of securing an accurate budget (which would favour large organisational units) and the goal of minimising managerial costs (which favours small organisational units).

Pooling years-Random fluctuations become less important as the time associated with a budget increases. Practice budgets will be more meaningful if they refer to a period longer than a year.

Excluding predictably expensive patients-A few patients with serious conditions may account for a large proportion of the unpredictable variation in a practice's expenditure. For conditions that are readily verified there may be an argument for transferring budgetary responsibility to the primary care group.

Excluding certain treatments-In the same way, certain treatments, such as those relating to severe mental illness, although rare, may have important implications for budgetary control. Simulation studies suggest that rare, costly procedures should not induce excessive financial risk for reasonably large practices. ${ }^{33}$ However, they were a major preoccupation in total purchasing pilot sites ${ }^{34}$ and consideration might therefore be given to transferring the whole or part of the costs of such treatments to a higher level authority.

Retention of a contingency fund-At the end of the budgetary period there must be an implicit transfer of expenditure from underspending practices to overspending practices. Better financial control may be secured by "top slicing" a certain amount from all budgets at the start of the period in order to create a contingency fund. This means that all practice budgets will appear relatively tight at the start of the period.

Careful analysis of variations from budgets-Before any action can be taken the primary care group must carefully examine the causes of variations from practice budgets. Such variations may arise from several sources, each of which has different policy implications. Defects in the capitation formula are a managerial issue. Variations in clinical practice might be addressed by increased use of peer review and clinical guidelines. Variations in contract prices might require discussions with providers or development of referral guidelines. Random variations in illness are by their nature largely resistant to policy intervention. Investigation of the causes of variations in expenditure may increase management costs, but it is difficult to see how a budgeting system can be made to function without putting in place the associated audit systems.

\section{Discussion}

Evidence from the business sector indicates that budget supervisors should investigate and act on variations from budgets intelligently and flexibly. This principle is likely to be of paramount concern as NHS budgets are devolved down towards practices. Furthermore, it is important to ensure that any sanctions (or rewards) attached to the budgetary system are commensurate with the degree of control exercised by the practice over expenditure. General practitioners' own actions are likely to have only a limited role in securing compliance, and therefore sanctions and rewards should be relatively modest. In particular, it would be unreasonable to allow practices to retain budget surpluses unless it was clearly understood that future deficits were to be made good from the retained balances. This also implies that overspending practices should be allowed to take forward deficits.

In practice it is difficult to imagine circumstances in which implementation of such a "hard" budgetary system is desirable. The limitations of any budgetary formula are likely to mean that there will be some persistent variation from fair budgets, even after variations in clinical practice have been accounted for. It is almost certainly the case, therefore, that any system of general practice budgets should be predominantly indicative and advisory, at least initially.

This paper has been presented in several forums, and I am grateful for all the feedback received, in particular from Mark Groom at the NHS Executive and an anonymous referee.

Funding: I am funded in part by the Department of Health under its health economics programme at the Centre for Health Economics.

Competing interests: None declared. 
1 UK Departments of Health. The new NHS. London: Stationery Office, 1997.

2 NHS Executive. HCHS revenue resource allocation to health authorities: weighted capitation formulas. Leeds: NHS Executive, 1997.

3 Petchey R. General practitioner fundholding: weighing the evidence. Lancet 1995;346:1139-42.

4 Goodwin N. GP fundholding: a review of the evidence. In: Harrison A, ed. Health care UK 1995/96. London: King's Fund, 1996.

5 Glennerster H, Matsaganis M, Owens P, Hancock S. Implementing GP fundholding: wild card or winning hand? Milton Keynes: Open University Press, 1992.

6 Dixon J, Glennerster $\mathrm{H}$. What do we know about fundholding? BMJ 1995:311:727-30.

7 Audit Commission What the doctor ordered. A study of GP fundholders in England and Wales. London: HMSO, 1996.

8 National Audit Office General practitioner fundholding in England. London: HMSO, 1994

9 Dixon J, Dinwoodie M, Hodson D, Dodd S, Poltorak T, Garrett C, et al. Distribution of funds between fundholding and non-fundholding practices. BMJ 1994;309:30-4.

10 Baines D, Tolley KH, Whynes DK. Prescribing, budgets and fundholding in general practice. London: Office of Health Economics, 1997.

11 Walley T, Wilson R, Bligh J. Current prescribing in primary care in the UK: effects of the Indicative Prescribing Scheme and GP fundholding. Pharmoeconomics 1995;2:320-31.

12 Mays N, Goodwin N, Bevan G, Wyke S. Total purchasing: a profile of national pilot sites. London: King's Fund, 1997.

13 Crump BJ, Cubbon JE, Drummond MF, Hawkes RA, Marchment MD. Fundholding in general practice and financial risk. BMJ 1991;302:1582-4

14 Martin S, Rice N, Smith P. Risk and the GP budget holder. York: Centre for Health Economics, University of York, 1997. (Discussion paper 153.)

15 NHS Executive Resource Allocation Funding Team. 1988/89 health authority revenue cash limits exposition book. Leeds: NHS Executive, 1988.

16 Newhouse JP, Manning WP, Keeler EB, Sloss ES. Adjusting capitation rates using objective health measures and prior utilisation. Health Care Financing Review 1989;10:41-54.

17 Roland MO, Bartholomew J, Morrell DC, McDermott A, Paul E. Understanding hospital referral rates: a users' guide. BMJ 1990;301:98-102
18 Ellwood S. Pricing of services in the UK NHS. Financial Accountability and Management 1996;12:281-301.

19 Emmanuel CR, Otley DT, Merchant K. Accounting for management control. London: Chapman and Hall, 1990.

20 Nove A. The Soviet economic system. London: Allen and Unwin, 1980.

21 Argyris C. The impact of budgets on people. Ithaca: Controllership Foundation, 1952

22 Hofstede GH. The game of budget control. London: Tavistock Institute, 1968

23 Buckley A, McKenna E. Budgetary control and business behaviour. Accounting and Business Research 1972;32:137-50.

24 Hopwood AG. An empirical study of the role of accounting data in performance evaluation, Journal of Accounting Research 1972;10(suppl):156

25 Otley DT. Budget use and managerial behaviour. Journal of Accounting Research 1978;16:122-49.

26 Govindarajan V. Appropriateness of accounting data in performance evaluation: an empirical examination of environmental uncertainty as an intervening variable, Accounting, Organizations and Society 1984:9:125-35.

27 Briers M, Hirst M. The role of budgetary information in performance evaluation, Accounting, Organizations and Society 1990;15:373-98

28 Macintosh $\mathrm{N}$. The social software of accounting and information systems. London: Wiley, 1985.

29 Smith P. Devolved purchasing in health care. London: Nuffield Trust, 1997. (Health economics series: paper 2.)

30 Glazer J, Shmueli A. The physician's behavior and equity under a fundholding contract. European Economic Review 1995;39:781-5.

31 Pollack H, Zeckhauser R. Budgets as dynamic gatekeepers. Management Science 1996;42:642-58.

32 Matsaganis M, Glennerster $\mathrm{H}$. The threat of "cream skimming" in the post-reform NHS. Journal of Health Economics 1994;13:31-60.

33 Bachmann MO, Bevan G. Determining the size of a total purchasing site to manage the financial risks of rare costly referrals: computer simulation model. BMJ 1996;313:1054-7.

34 Bevan G, Baxter K, Bachmann M. Survey of budgetary and risk managemen of total purchasing pilot projects 1996/97. London: King's Fund, 1998.

(Accepted 12 November 1998)

\title{
A model for clinical governance in primary care groups
}

\author{
Richard Baker, Mayur Lakhani, Robin Fraser, Francine Cheater
}

Clinical governance is the core component of the new quality programme for the NHS (see box on next page) announced in the consultation document $A$ First Class Service. ${ }^{1}$ It is described as "a framework through which NHS organisations are accountable for continuously improving the quality of their services and safeguarding high standards of care by creating an environment in which excellence in clinical care will flourish." It will be the central focus for assuring the quality of care and addressing the issue of providing accountability through the Commission for Health Improvement. The activities of the commission will reflect national and local priorities as identified by the National Institute of Clinical Excellence and health improvement programmes respectively. Although A First Class Service included details about the structure and functioning of clinical governance in health service trusts, arrangements for primary care groups were not specified. In this paper, we suggest a possible model for clinical governance in primary care groups.

\section{Model precepts}

The model is based on three underlying precepts:

- Clinical governance encompasses both quality improvement and accountability-systems for both must be developed fully if the highest levels of quality of care and professional performance are to be shown to have been achieved;

- Quality improvement and accountability depend on effective methods of changing performance-without

\section{Summary points}

Clinical governance is central to the NHS quality programme, but how it will operate in primary care groups remains unclear

Although many activities included in the new concept of clinical governance are already being undertaken, these need to be coordinated

A model of governance that addresses the core tasks of defining, accounting for, and improving quality and incorporates evidence on effective methods of changing performance is suggested

This model can improve professional, practice, and primary care group performance

It shows how groups can introduce and develop clinical governance and how health authorities and the Commission for Health Improvement can monitor progress

these, clinicians and primary care groups cannot improve quality or account for it. Fortunately, there is growing evidence about the effectiveness of methods of changing performance that can be used to guide arrangements for clinical governance ${ }^{3-5}$;
Eli Lilly National Clinical Audit Centre, Departmen of General Practice and Primary Health Care, University of Leicester, Leicester General Hospital,

Leicester LE5 4PW Richard Baker, director

Mayur Lakhani,

lecturer

Robin Fraser,

professor

Francine Cheater

senior lecturer

Correspondence to:

Dr Baker

rb14@le.ac.uk

BMJ 1999;318:779-83 